\title{
Employment of Active Learning at HEIs in Bangladesh to Improve Education Quality
}

\author{
Faieza Chowdhury ${ }^{1}$ \\ ${ }^{1}$ Faculty of Business Administration, American International University-Bangladesh (AIUB), Dhaka, \\ Bangladesh
}

Correspondence: Faieza Chowdhury, Faculty of Business Administration, American International University-Bangladesh (AIUB), Dhaka, Bangladesh. E-mail: chowdhury.faieza@gmail.com

Received: April 6, 2016

doi:10.5539/ies.v9n10p47
Accepted: May 6, $2016 \quad$ Online Published: September 22, 2016

URL: http://dx.doi.org/10.5539/ies.v9n10p47

\begin{abstract}
In recent years, education quality and quality assessment have received a great deal of attention at Higher Education Institutions (HEIs) in Bangladesh. Most of the HEIs in Bangladesh face severe resource constraints and find it difficult to improve education quality by improving inputs, such as better infrastructure and modernized classroom facilities. Thus, in response to the present government's demand to improve the quality of education at HEIs in Bangladesh, it is imperative to formulate plans that are more cost-effective. According to some previous studies, the quality of education depends largely on the teaching-learning process. These studies affirm that, with limited resources at hand, the employment of active learning in the classroom is one of the most effective ways to improve education quality. To conduct this qualitative research, we utilized multiple sources of data, including semi-structured and in-depth interviews, descriptive observations and self-administered questionnaires. This paper aims to explore three related issues: What are the various active learning strategies that can be employed by the instructors at HEIs in Bangladesh? What are the potential factors that can hinder the implementation process? Finally, what recommendations can be provided on how to successfully implement active learning strategies in the classroom? The findings suggest that a lack of teacher training and student prior experience in an active learning environment, large class sizes, excessive curriculum loads and students' academic backgrounds are some common factors that can hinder the implementation of active learning in Bangladesh. The findings of this study can be instrumental for HEIs in Bangladesh as they aspire to improve their education quality.
\end{abstract}

Keywords: active learning, Bangladesh, education quality, HEIs, teaching strategies

\section{Introduction}

In an educational setting, quality is a complex issue. According to Grisay and Mahlck (1991), the concept of education quality can be divided into three interrelated dimensions: (input), the quality of human and material resources available for teaching; (process), the quality of teaching and practice; and (output), the quality of results. The input-process-output framework of quality assessment is popular, but there is much less agreement regarding how this framework should be implemented in practice. In the past few years, due to the growing number of students at HEIs in Bangladesh, it has become imperative to improve the quality of education. Most often, the HEIs in Bangladesh try to improve education quality through improving inputs such as the campus, classroom facilities, laboratory and library facilities or other teaching aids. However, there is a growing emphasis on improving quality in the educational setting through improvements in the teaching-learning process. Previous research indicates that the way teachers teach in the classroom is a critical factor in any reform designed to improve education quality (Niyozov, 2001; UNESCO, 2004). In many low income countries, there has been a shift in the educational priorities of the government towards educational reforms that emphasizes a movement from a didactic teaching approach to a constructivist-oriented active learning style. In 2010, the government of Bangladesh published their National Education Policy, which indicates the government's commitment to teaching strategies that "promote more interactive teaching methods to develop the creative faculties and skills of children" (Ministry of Education, p. 15). To improve the higher education system in Bangladesh toward a global standard, the Ministry of Education, with the assistance of the World Bank, has undertaken a Higher Education Quality Enhancement Project (HEQEP) that aims at improving the quality of teaching-learning and research 
capabilities of HEIs in Bangladesh. Considering Bangladesh's commitment to meet the objectives envisaged in these national policy directives, it is imperative to redesign teaching strategies, abandon the prevalent "chalk and talk" mode of teaching and move towards student-centered active learning strategies (Park, 2012).

One of the earliest international documents that highlighted active approaches to teaching and learning was the "World Conference on Education for All (EFA): Meeting Basic Learning Needs", which was jointly organized by UNDP, UNESCO, UNICEF and the World Bank in Thailand in 1990. Later, at the World Education Forum in Dakar, Senegal, most governments and EFA partners, including Bangladesh, committed to achieve Education for All (EFA). In that forum, 10 elements were identified for quality education, including well-trained teachers using active learning strategies (UNESCO, 2000). Focusing on Bangladesh, Farrell (2002) argues that employment of active learning strategies in class can produce remarkable learning gains among even the poorest and most disadvantaged children (Park, 2012). Despite the concern of the government for improving the quality of education in higher education institutions, the current condition of most of the HEIs in Bangladesh is quite disturbing. With few exceptions, most of the HEIs in Bangladesh have a large influx of students every year but fail to provide high quality education. Students of most HEIs are not mastering basic skills and lack creative thinking, analytical abilities and have low achievement in the practical work sphere.

In the context of the educational setting, there is a strong link between the quality of education and active learning strategies. At present, although there is a major emphasis on the implementation of active learning strategies in Bangladesh, little elaboration is given by the policy makers to guide HEIs regarding the incorporation of active learning strategies in the classroom. In this study, we aim to explore the different active learning strategies that HEIs in Bangladesh can incorporate to improve the teaching learning process. We also examine the university, teacher and student variables that can militate against the implementation of active learning strategies. Finally, we provide some recommendations that can help teachers, researchers, key educational policy makers and other education experts to understand how active learning strategies can be successfully implemented at HEIs in Bangladesh.

\section{Literature Review}

\subsection{What Does "Quality" Mean in An Educational Context?}

The term "quality" is derived from the Latin word "qualitas," which means the degree of excellence of a thing (Oxford Dictionary, 2003). However, when quality is used in an educational context, it is important to define the term clearly as different professionals, such as researchers, educators and politicians may interpret it differently. According to Murgatroyd and Morgan (1994), quality can be defined in two ways: one is related to quality assurance and the other is related to the consumers' point of view. Both the definitions are as follows:

"Quality assurance refers to the determination of standards, appropriate methods and quality requirements by an expert body, accompanied by a process of inspection or evaluation that examines the extent to which practice meets these standards".

"Consumer-driven quality refers to a notion of quality in which those who are the recipients of a product or service make explicit their expectations for this product or service, and quality is defined in terms of meeting or exceeding the expectations of customers" (Ashraf, Ibrahim, \& Joarder, 2009).

According to Adams (1993), the terms quality, efficiency, effectiveness and equity can be used interchangeably. The meaning of educational quality is grounded in values, cultures and traditions; it may be specific to a given nation, province, community, school, parent or individual student. Even if there is a lack of disagreement on what quality is, there often is agreement that it should be approved (Serbessa, 2006).

World Bank (1995) states that:

"Quality in education is difficult to define and measure. An adequate definition must include student outcomes. Most educators would also include in the definition the nature of the educational experiences that help to produce the outcome- the learning environment".

One problem in defining education quality arises from the fact that there are many aspects of education that can be used as the focal element: infrastructure, school buildings, administration, teacher training, educational materials, teaching or achievements. All of these elements are interrelated and a serious deficit in one is likely to have implications for the quality of others (Kellaghen \& Greaney, 2001).

According to the UNICEF (2000), the desirable five dimensions of quality, as identified in the Dakar Framework, are learners, environments, content, processes and outcomes. Similar to the dimensions of education quality identified by UNESCO (Pigozzi, 2004), those recognized by UNICEF draw on the philosophy of the Convention 
on the Rights of the Child. The Convention on the Rights of the Child stresses a child-centered approach to teaching and learning.

When parents invest their money in a child's education, they expect that it will develop the child's creative thinking and the child will acquire the necessary skills, values and attitudes required to lead a successful and productive life. Lockheed and Verspoor (1991) point out that in order for education to achieve these goals, it is important for the educational institutions to meet some minimum education quality standards in terms of minimum inputs (facilities, teaching materials, qualified teachers, parents and community support), processes (effective leadership, monitoring and evaluation, accountability, community participation, effective teaching and learning process and student assessment) and outputs (high student learning, societal and individual returns).

Furthermore, Lockheed and Verspoor (1991) note that to improve economic and social development in developing countries, it is important to offer essential skills to the children at the educational level. Such essential skills include literacy, numeracy, communication, analysis and problem solving. This indicates that good quality education is of central importance for national development in low income countries (Serbessa, 2006).

In Bangladesh, there has been a major growth in the number of universities providing higher education since the enactment of Private Universities Act in 1992. In 2010, there were 51 private universities in Bangladesh, but as of February 2016, the number of approved private universities reached 92. According to the 38th Annual Report of UGC for 2011, the total number of students in private universities more than tripled to 280822 in 2011 from 88669 six years earlier in 2005. Some intellectuals in Bangladesh raised a number of criticisms regarding the newborn private universities (Haque, 2004; Ahmed, 2003; Rahman, 2003; Sumon, 2004; Siddiqi, 2006; Khan, 2004). Although this rapid growth of private universities in Bangladesh increased access to higher education, the question around education quality remains. Some key issues are the qualifications of teachers and the relevance of teaching practices (Policy \& Operations Evaluation Department (IOB) of the Netherlands, Ministry of Foreign Affairs, 2011).

Recently, the government of Bangladesh funded a project named the HEQEP (Higher Educational Quality Enhancement Project) in which education quality and quality assessment received a great deal of attention at HEIs in Bangladesh. There are a large number of reports and theoretical works in which research scholars have provided different views on the issue of education quality in the context of Bangladesh. According to Andaleep (2003), there are seven crucial factors for fostering higher education in Bangladesh: teaching quality, method, content, peer quality, direct facilities and political climate. Lamanga (2002) noted that there are three aspects that must be considered in measuring education quality at private universities in Bangladesh: quality of teaching and research, responsiveness to the demands of the labor market and equity. Aminuzzaman (2007) noted that in Bangladesh, most of the departments at private universities do not have a long term national vision connected to education, but such vision is crucial to improve education quality. To the author's best knowledge, this is one of the very few studies to explore how HEIs in Bangladesh can improve teaching and learning processes with the aid of progressive pedagogies, such as active learning, to improve education quality.

\subsection{Active vs. Traditional Learning}

Lecturing is a time-tested and long venerated teaching style that is frequently utilized in higher education institutions throughout the world (Svinicki \& Mckeachie, 2011; Lambert, 2012). However, it is a traditional learning strategy in which students just sit passively, often disconnected from the lecture and doing other things such as Facebooking, text messaging or homework for other classes (Millis, 2012). Bligh (2000) notes that the lecture method is a relatively poor teaching approach for maintaining student attention. Some researchers such as Stuart and Rutherford (1978) note that the concentration of most students during the lecture begins to decline after 10-15 minutes.

The traditional lecture method is often contrasted to active learning. In an active learning environment, the instructor will spend greater portion of class time helping students develop their understanding and skills and a smaller proportion of time transmitting information. Instructors who employ active learning in class provide opportunities for students to apply and demonstrate what they are learning through various structured, interactive activities.

In contrast to traditional lectures, active learning involves (a) the instructor giving a lecture with periodic pauses for class/group activities; (b) the instructor asking questions that require responses from students, which provides opportunities to resolve misunderstandings or confusion; (c) the students' comprehension of the lecture continuously being monitored by the instructor during the class session through short exercises or assessments. 
The most commonly cited definition of active learning is suggested by Bonwell and Eison (1991). They note that active learning is the process of involving students in doing things and helping them to think about what they are doing. Active learning refers to wide range of activities introduced into the classroom to encourage students to share their thoughts and ideas with a partner, a small group or entire class. It can also foster thinking creatively and critically, exploring personal attitudes and values of the students (Millis, 2012).

Stern and Huber (1997) provided two definitions of active learning. According to them, active learning means learners will be provided opportunities to decide what aspects of a particular educational field they would like to study. Secondly, active learning also refers to the degree to which learners are challenged to use their mental abilities while learning.

Berry (2008) postulates that active learning comprises four key elements: (1) critical thinking, (2) individual responsibility for learning, (3) involvement in open-ended activities, and (4) organization of learning activities by the teacher.

In 1966, John Dewey emphasized the "learning by doing" approach. He noted that students must be engaged in an active quest for learning new ideas and solving real life problems (Dewey, 1966). Silcock and Brundrtt (2001) defined the learner-centered active approach as a process where the tutor guides the learner rather than asserting control to achieve certain targeted learning goals.

Although all learning is active, some teaching and learning strategies foster more active participation of students than others. More participatory forms of active learning discourage passive roles for students and encourage them to take more responsibility for their own learning process (Kane, 2004; Mayer, 2011; Niemi, 2002; Reynolds, 1998; Stern \& Huber, 1997).

Prince (2004) highlighted the effectiveness of active learning. He discovered that introducing active learning into the classroom can significantly improve recall of information by the students. Carl-Weiman, a Nobel winning physicist, found that in identical classes, students who were taught by teaching assistants with the aid of active learning strategies demonstrated better performance than those students who learned from an esteemed professor using a traditional lecture-based approach (Haak, HilleRisLambers, Pitre, \& Freeman, 2011).

\subsection{Active Learning Strategies}

In most of the HEIs in Bangladesh, teaching has been traditionally conducted through the means of conventional teaching techniques, such as the use of lectures, in which course materials, problems and assessment modes have been determined by the instructor and transmitted to students in various lectures. This traditional "chalk and talk" approach in which students are only the passive recipient of knowledge is not suitable for today. Active learning is a learner-centered process of teaching in which the focus shifts from teaching to guiding. In a learner-centered approach, teachers become the guides and mentors of the students, helping students develop various skills including writing, communication, analytical and creative skills. Adler (1999) notes that active learning allows students to have an in-depth understanding of the subject rather than a superficial understanding. If the instructor uses active learning strategies in the classroom, then students will benefit as it will enhance their learning experience and help them to better understand the key concepts of a course.

However, a shift from traditional learning to active learning requires instructors to skillfully select the active learning strategies that will be applied in the classroom and pre-plan what learning outcomes they want to achieve from each strategy. It is also important for the instructor to inform the students regarding the various active learning strategies that will be utilized in the classroom in advance and how students can benefit from each strategy. Any expectation related to student involvement or participation must be communicated from the onset to avoid confusion or difficulty. There are various active learning strategies that can be integrated into a university course curriculum in different ways. However, the strategy an instructor chooses to follow depends on the course content and the class demographic (Dias, 2011).

In this section, we will discuss the various active learning strategies that can be applied by the instructors at HEIs in Bangladesh. Some of the active learning strategies can be easily and quickly integrated within the existing teaching practices, while other strategies require more investment of time and planning.

\subsubsection{Pause Procedure}

Pause procedure is a technique that can be used to promote greater student engagement through the use of strategic pauses during the lecture. In this method, the instructor will pause the lecture and provide time for the students to review their notes, discuss the topics with classmates or undertake other activities that allow them to clarify and retain the material that has been discussed in the class. According to Rowe (1980), there should be pauses in a lecture at 8-12 minute intervals of at least two to three minutes to enhance active learning. However, 
the pause procedure is effective only when students utilize the pauses to carryout activities that help them to comprehend the materials discussed in the class.

\subsubsection{Think-Pair-Share}

This is a collaborative learning strategy that was first developed by Mills, Lyman, and Davidson (1995). In this strategy, information is provided to students by the instructor through a reading assignment, short lecture, video tape etc. The instructor provokes students' thinking with a question and students are instructed to think about that question or write a short note. Then, students are encouraged to pair-up with a classmate and share their responses with their partner. In the end, the teacher would ask the pairs to share their findings with the rest of the class. This strategy promotes classroom participation as it encourages a high degree of pupil response, allows all students to share their findings and to formulate thoughts before sharing them with others and fosters high-order thinking skills.

\subsubsection{Clickers and Personal Response Cards}

Clickers or class room response systems are hardware and software that can be employed to promote active learning in the classroom. Eison (2010) notes that Mac Arthur and Jones have identified 56 publications reporting the use of clickers in college level classes and found students having a positive attitude towards the technology, highlighting many benefits and few drawbacks associated with its use. Another tool that can be utilized in the classroom is response cards. Response cards can be provided to the students at the onset of the class so that every student in the class can respond to the instructors' questions by displaying the cards. Some previous researchers (Marmolejo, Wilder, \& Bradley, 2004; Gardner, Heward, \& Grossi, 1994; Kellum, Carr, \& Dozier, 2001; Christle \& Schuster, 2003) suggest that, in contrast to the traditional way of students respond by raising their hands to the instructor's question, response cards can be utilized to enhance classroom participation.

\subsubsection{Roleplay}

If designed in a skillful manner, roleplays can be an effective tool to promote active learning in the classroom. In a roleplay, students have to immediately apply the concepts that they have learned in the class as they are placed in the role of a decision-maker. This is an excellent student engagement strategy that allows students to interact with their peers and complete the task given to them by assuming a specific role or character. Roleplaying can benefit students by allowing them to think beyond the confines of the classroom setting, developing their critical thinking skills and creating opportunities to apply the course content in a relevant, real world context.

\subsubsection{Games/Puzzles/Contests}

Instructors can use problem solving games, puzzles and contests to liven up the classroom and add the 'fun' element in their teaching process. Such activities provide the instructor with an informal method to assess the students' mastery of the course materials. According to Verhoeff (1997), "Marcus Verrius Flaccus, a Roman teacher famous in the late $1^{\text {st }}$ century $\mathrm{BC}$, is credited with having introduced the principle of competition among his students as a pedagogical aid. He awarded his students with attractive books as prizes" (Eison, 2010).

\subsubsection{Debates}

In order for the students to become successful in the practical work sphere, it is important for them to convey their knowledge not only through formal essays and examinations but also through formal and informal oral communication. Classroom debates can enhance students' participation and discussions and encourage students to actively critique various social and political issues.

\subsubsection{Case Study}

The case study method of teaching was first introduced at Harvard Law School in 1870 (Weaver, Kowalski, \& Pfaller, 1994). The use of case studies in the classroom can enhance critical thinking and classroom discussion. According to Husock (2000), case studies are narratives designed to serve as the basis for classroom discussion. Cases can be used to test the ability of the students to relate and apply the concepts they are learning in the class to real world scenarios.

\subsubsection{Brainstorming Session}

This is a technique that can be utilized in class to promote group thinking, to generate many ideas quickly or to solve critical problems. This technique actively engages students and encourages class participation as one person's ideas spark ideas for another. To conduct a brainstorming session successfully, it is important for the instructor to pre-select the topic or problem and then facilitate the session, limiting the time to 5-10 minutes. The teacher acts as a facilitator and moves from group to group during the brainstorming session. 


\subsubsection{Visitors/Guest Speakers in the Classroom}

Instructors can invite visitors to the classroom who are experts in a given field/discipline to share their practical knowledge and experiences with the students. It is important to provide visitors prior information about the class, such as the topics that the students are learning, the age group of the students, etc. The instructors should invite guest speakers who are effective and knowledgeable to enhance student participation in the classroom. However, this strategy works most effectively if the instructor skillfully pre-plans the full session with both the students and the guest speaker. If the session is conducted properly, then guest speakers can excite students in a given topic and stimulate lively in-class discussions.

\subsubsection{Real or Virtual Field Trips}

Instructors can carefully plan and prepare educational field trips for students that allow them to learn outside the traditional classroom setting. Field trips offer opportunities for students to obtain firsthand experience of the practical work environment and relate this to their academic knowledge. Field trips, if designed properly, can achieve a wide range of powerful learning outcomes and add both excitement and instructional impact to the class. Instructors can plan field trips to various sites such as museums, government or industrial sites, natural preservation areas, etc. The destination for the field trip can be selected by the instructor based on course context and the discipline to which it relates.

\subsubsection{One-Minute Paper}

At the end of a teaching session, instructors can use this strategy to verify whether students understand the concepts discussed during the class. This is a simple strategy in which instructors provide a few minutes to students at the end of every class and ask the students to respond individually, in writing to a question related to the concepts covered in class. The responses of the students will help the instructors to understand the student comprehension level and identify any common areas of difficulty. The instructors can address the problem areas noted by the students at the beginning of the next lecture (Cameron, 2010).

\subsubsection{Virtual Aids}

Instructors can use virtual aids such as graphics, word clouds, concept maps, films and videos to elevate students' interest in the course materials and improve their comprehension levels in certain topics of the course. Use of virtual aids can stimulate focused critical thinking and personal reflection by students. Students can benefit as it will help them to understand the key concepts more clearly and realize how different concepts relate to each other.

\subsubsection{Presentations}

Designing a course that requires students to give a classroom presentation either individually or in small groups can encourage students to play an active role in their learning process. Students can conduct research on a specific topic and give a presentation on that topic in front of the class. This strategy can be utilized to enhance student interest and curiosity about the course content and explore the topics discussed in the class more elaborately. It can also help students overcome nervousness related to public speaking and become more confident in sharing their ideas and views with others.

Despite the fact that most educators in Bangladesh agree that traditional teaching approaches where students are placed in a passive role of acquiring knowledge is undesirable, there is ample evidence that suggest that this is the norm in the vast majority of HEIs in Bangladesh. However, in recent years, several initiatives have been undertaken by the government of Bangladesh, donors and NGOs to promote active learning, which puts a strong emphasis on students taking an active role in the classroom by asking questions, working in groups and sharing their opinions and views with others (Policy \& Operations Evaluation Department (IOB) of the Netherland, Ministry of Foreign Affairs, 2011).

\section{Purpose and Methodology}

The main objective of this paper is to direct attention to the various active learning strategies that instructors at HEIs in Bangladesh can incorporate into their classrooms. This paper also sheds light on the potential factors that can hinder the integration of active learning strategies in Bangladesh and finally provides recommendations for successful implementation. For the purpose of this study, we have used multiple forms of qualitative data, including descriptive observations, self-administered questionnaires including semi-structured and in-depth interviews of various participants selected from five universities in Bangladesh. According to Denzin and Lincoln (2003), qualitative research focuses on meanings and attempts to understand the culture and beliefs of those being studied. Furthermore, Corbin and Strauss (2007) note that the most important reason that a 
researcher conducts qualitative studies is so that the world can be viewed vicariously from the perspectives of the research participants with the hope of developing empirical knowledge from the discoveries.

\section{Discussion}

If we study the research that focused on the implementation of active learning in classes, a substantial gap exists between theory, policy and practice in many low-income countries. Research indicates that many initiatives undertaken in low-income countries that claim to follow learner-centered active learning share many characteristics with conventional teaching approaches (Barrett et al., 2007; Menon, 2008). Despite the fact that most educators in Bangladesh support progressive learning pedagogies such as active learning, the implementation process can be hindered due to some teacher, university and student variables.

\subsection{Teachers' and Students' Backgrounds in Bangladesh}

In every society, the attitudes and values of the people can vary. These attitudes of the people in a society can influence the learning and teaching practices that are adopted by educators. Most of the popular learning and teaching models are based on the framework of developed countries hence attempting to copy a teaching model from one society to another without tailoring it to the local culture may not be successful. In Bangladesh, the tradition of teaching has been dominated by teacher-centered didactic lectures. A vital source of such conventional teaching lies in the background of most educators and teachers. Some previous studies affirm that teachers who were educated in a traditional setting often prefer to teach their students using the same style. According to Dyer et al. (2004), there is often a cultural gap between progressive and conservative educationalists; hence, the ability to adapt to new innovative teaching practices may be constrained by lack of teacher training and development programs. The background of a student is another important variable that can influence the implementation of active learning at HEIs in Bangladesh. Most of the students at HEIs in Bangladesh come from Bengali medium schools in which Bangla is the main medium of instruction and students are often not exposed to English to a substantial extent. However, most of the HEIs in Bangladesh, especially the private universities, choose English as their main operational language to keep up with high international education standards. As a result, most of the students, especially those from Bengali medium schools, face severe challenges in understanding the lectures and participating in the class discussions, as all of the lectures, classroom interactions and exams are usually conducted in English. Therefore, to overcome this problem, it is important for HEIs to offer compulsory remedial English courses designed to help weak students develop their English skills. Hence, the background and the preexisting knowledge of students can also influence their ability to actively participate in the classroom.

\subsection{Lack of Resources and Proper Teaching Settings}

Creative and innovative teaching does not flourish in a vacuum. The employment of active learning strategies in the classroom requires the meeting of minimum standards of physical infrastructure and other resources. First, there must be enough space in the classroom so that proper seating arrangements can be made by the instructor to carryout group discussions and other interactive activities. Often, the classrooms in Bangladesh have front-to-back fixed seating arrangements that only promote one-way communication. The front-to-back seating arrangement encourages students to focus mainly on the instructor; however, such a seating arrangement is not suitable for group discussions in class. Moreover, larger class sizes (often greater than 40 students) can also restrict the use of certain active learning strategies, as it can be difficult for the instructor to include all students in the class discussions. Second, handouts, notes or students' handbook/booklets must be designed in a way that promotes active learning in the classroom. The learning materials provided to the students must contain short exercises or problems that allow students to actively participate and engage in group discussions in the class. At present, most of the instructors at HEIs in Bangladesh provide teaching materials to the students that are just large amounts of information provided for memorization purposes. It is important to prepare the course materials for students in a way that promotes independent thinking and active learning in the class. Cross (1987) claims that students who are actively involved in the learning process learn more than passive recipients of information. Chickering and Gamson (1987) note that learning is not a spectator sport. When students are just sitting in the class listening to the teachers, memorizing prepackaged course materials and spitting out answers, they do not learn much. They state that it is important for students to talk about what they are learning, relate it to real life experiences and then apply that learning to their daily lives.

Third, the excessive curriculum load that needs to be covered in every semester is another factor that can hinder the utilization of active learning strategies. Teachers often complain that, due to excessive materials that they must cover in every lecture, they never have the chance to discuss topics in-depth or engage in group activities. Due to excessive teaching materials, the only way teachers think that they can cover everything within the given 
time limit is to deliver their lectures in a formal didactic style that requires less distraction for students. Hence, due to the excessive curriculum load, class participation is often discouraged by the teachers, which can hinder active learning. Finally, unavailability of required teaching aids in the classroom, such as projectors, speakers or high speed internet facilities, can also effect the employment of certain active learning strategies.

\subsection{Students' Lack of Prior Experience in an Active Learning Environment}

The prior experience and expectation of students can affect active learning. The successful implementation of active learning strategies in the class requires students to take initiative and responsibility for their own learning process. In Bangladesh, most of the students at HEIs come from a background in which they have been too dependent on teachers from early stage. Hence, most students tend to be passive recipients in class. The students normally listen to the lectures and remain silent in the class unless their participation is demanded or requested by the teachers. This mainly arises due to their lack of prior experience in an active learning environment. Students often prefer to remain silent in class, as they believe that responding without being engaged by the teacher will be considered impolite. Moreover, most students often tend to think that their responsibility as a student is just to listen to the lectures, take notes and respond to questions only when requested. Hence, the mindset of most Bangladeshi students often leads to a lack of self-regulatory learning and more "spoon-feeding". For the effective application of active learning strategies in the classroom, it is important for Bangladeshi students to change this attitude and mindset. Active learning requires all students in the class to be more proactive and reflect on what they are learning through various interactive classroom activities.

\section{Conclusion}

In Bangladesh, most of the educators broadly agree that the conventional style of teaching in which students are placed in a passive role is undesirable. Nevertheless, to integrate progressive pedagogies such as active learning at HEIs in Bangladesh, it is important for everyone to embrace some changes. The HEIs must provide training and appropriate guidelines to their current teachers regarding how they can incorporate active learning as part of their teaching process. At present, although (HEQEP) Higher Education Quality Enhancement Project in Bangladesh is providing one-time training opportunities to a limited number of professors involved in the project managers department, such training is essential for all junior and senior teachers at every HEI in Bangladesh (Mazumder, 2012). The HEIs in Bangladesh can provide their newly appointed teachers mandatory training on teaching methodology and pedagogical research. HEIs can introduce special training programs or workshops for senior teachers so that they can also be updated with the latest developments and trends on teaching pedagogy around the world. HEIs also need to provide teachers with the appropriate resource support and teaching aids to conduct active learning in the classroom. The classroom needs to be designed in a way that will foster group discussions and interactive sessions among the students. The HEIs also need to ensure that the curriculum loads are not excessive for each semester so that instructors can cover the course materials with the employment of active learning strategies. Further, HEIs should also offer compulsory remedial English courses to all of the first semester students to help them develop their English communication skills.

Instructors are often aware of active learning strategies but are reluctant to incorporate such strategies in the classroom, as they frequently regard such strategies as unworkable and unintelligible. The teachers in HEIs need to realize that integration of active learning can make their teaching more effective. The instructors need to design student handouts or booklets in a way that will allow students to participate and demonstrate their understanding and learning in the class. One way that instructors can do this is by incorporating different in-class tasks into the course booklet, such as cases, short assignments and class problems. Other simple active learning strategies that instructors can easily apply in their classes are debates, roleplays, think-pair-share, presentations, one-minute papers and brainstorming. In addition, the use of computers, videos and reality-based simulation software can facilitate an active learning environment in the classroom. Such active learning strategies can help students to develop their critical thinking, analytical abilities and communication skills.

Despite the various benefits of active learning, there is ample evidence that suggest that most of the instructors at HEIs in Bangladesh still follow the traditional didactic teaching style. One limitation of formal didactic teaching is that it assumes that all learners are same and that one style of teaching will meet the needs of every student. It is crucial for instructors to realize that learners vary widely in terms of personal learning abilities, backgrounds and preexisting knowledge; thus, a single teaching strategy will not be appropriate for all of the students in the class. Learning is a unique experience for each individual, and thus it is vital to use various teaching strategies in the classroom to reach out to most of the students. Instructors need to use active learning strategies that promote interaction between the teacher and students and among the students in the class. Finally, for the successful implementation of active learning in the classroom, students must learn to take responsibility for their own 
learning process. Students should learn to adapt themselves to the active learning environment, which encourages an independent, purposive and reflective way of learning.

Despite internal and external pressure from the government and other regulatory bodies to improve education quality at HEIs in Bangladesh, it is difficult to attain a better quality of education by improving inputs such as a good campus, improved classroom tools, updated library facilities and modernized lab equipment in the short run because that would require a large investment of time and resources. Thus, with limited resources and time at hand, the employment of active learning in the classroom can be one of the most effective ways to improve the quality of education at HEIs in Bangladesh.

\section{References}

Adams, D. (1993). Defining Educational Quality. Arlington, VA: Institute for International Research and University of Pittsburgh, USAID, Improving Educational Quality Project.

Adler, J. (1999). The Dilemma of Transparency: Seeing and Seeing through Talk in the Mathematics Classroom. Journal for Research in Mathematics Education, 30(1), 47-64. http://dx.doi.org/10.2307/749629

Ahmed, M. (2003). The Standard of Education in Private Universities: Current Trends and Transformation. Observer.

Aminuzzaman, S. (2007). Overview of Quality Assurance in the context of Bangladesh. Paper presented in a workshop organised by American International University Bangladesh (AIUB), Dhaka, Bangladesh.

Andaleeb, S. S. (2003). Rejuvenating the Nation's Higher Education System. Proceeding of the workshop organised by International University of Business Agriculture and Technology. Dhaka, Bangladesh.

Ashraf, M. A., Ibrahim, Y., \& Joarder, M. H. R. (2009). Quality education management at private universities in Bangladesh: An Exploratory Study. Pendidik dan Pendidikan, JIL, 24, 17-32.

Barrett, A., Sajid, A., Clegg, J., Hinostroza, J., Lowe, J., Nikel, J., . . Yu, G. (2007). Initiatives to improve the quality of teaching and learning: A review of recent literature. Background paper prepared for the Education for All, global monitoring report 2008. EdQual working paper no. 11. Bristol: EdQual.

Berry, W. (2008). Surviving lecture: A pedagogical alternative. College Teaching, 56, 149-154. http://dx.doi.org/10.3200/CTCH.56.3.149-153

Bligh, D. A. (2000). What's the use of Lectures? San Francisco: Jossey-Bass.

Bonwell, C. C., \& Eison, J. A. (1991). Active Learning: Creating Excitement in the Classroom. ASHEERIC Higher Education Report No. 1, George Washington University, Washington, DC.

Cameron, B. J. (1999, reprinted 2010). Active Learning, Green Guide \#2. London, ON: Society for Teaching and Learning in Higher Education (STLHE).

Chickering, A. W., \& Gamson, Z. F. (1987). Seven principles for good practice in undergraduate education. AAHE Bulletin, 39(7), 3-7.

Christle, C. A., \& Schuster, J. W. (2003). The effects of using response cards on student participation, academic achievement, and on-task behavior during whole-class, math instruction. Journal of Behavioral Education, 12, 147-165. http://dx.doi.org/10.1023/A:1025577410113

Corbin, J. M., \& Strauss, A. L. (2007). Basics of Qualitative Research: Techniques and procedures for developing grounded theory (3rd ed.). Los Angeles, CA: Sage.

Cross, P. (1987). Teaching for Learning. AAHE Bulletin, 39(8), 3-7.

Denzin, N. K., \& Lincoln, Y. S. (2003). The Landscape of Qualitative Research: Theories and issues (2nd ed.). Thousand Oaks, CA: Sage.

Dewey, J. (1966). Democracy and Education. Free Press, New York.

Dias, M. (March 2011). Teaching Strategies for Active Learning. Center for University Teaching. Ottawa.

Dyer, C., Choksi, A., Awasty, V., Iyer, U., Moyade, R., Nigam, N., . . Sheth, S. (2004). Knowledge for teacher development in India: The importance of 'local knowledge' for in-service education. International Journal of Educational Development, 24(1), 39-52. http://dx.doi.org/10.1016/j.ijedudev.2003.09.003

Eison, J. E. (2010). Using Active Learning Instructional Strategies to Create Excitement and Enhance learning (Unpublished Manuscript).

Gardner, R., Heward, W. L., \& Grossi, T. A. (1994). Effects of response cards on student participation and 
academic achievement: A systematic replication with inner-city students during whole-class science instruction. Journal of Applied Behavior Analysis, 27, 63-71. http://dx.doi.org/10.1901/jaba.1994.27-63

Grisay, A., \& Mahlck, L. (1991). The quality of education in developing countries: A review of some research studies and policy documents. Paris: International Institute of Educational Planning.

Haak, D. C., HilleRisLambers, J., Pitre, E., \& Freeman, S. (2011). Increased structure and active learning reduce the achievement gap in introductory biology. Science, 332, 1213-1216. http://dx.doi.org/10.1126/science. 1204820

Haque, A. N. M. N. (2004). Growing Worries Over Private Universities. Observer.

Husock, H. (2000). Using a Teaching Case. Kennedy School of Government Case Program. Harvard University.

Kane, L. (2004). Educators, learners and active learning methodologies. International Journal of Lifelong Education, 23(3), 275-286. http://dx.doi.org/10.1080/0260/37042000229237

Kellaghan, T., \& Greaney, V. (2001). Using assessment to improve the quality of education. Paris: UNESCO (International Institute for Educational Planning).

Kellum, K. K., Carr, J. E., \& Dozier, C. L. (2001). Response-card instruction and student learning in a college classroom. Teaching of Psychology, 28, 101-104. http://dx.doi.org/10.1207/S15328023TOP2802_06

Khan, M. M. H. (2004). Private Universities and Their Problems. Financial Express.

Lamanga, C. Z. (2002). Strategic view of the development of Higher Education: Bangladesh AIUB perspective. Dhaka: A1 Publication.

Lambert, C. (2012). Twilight of the Lecture. Harvard Magazine, 23-27.

Lockheed, M. E., \& Verspoor, A. M. (1991). Improving Primary Education in Developing Countries. New York: Oxford University Press.

Marmolejo, E. K., Wilder, D. A., \& Bradley, L. (2004). A preliminary analysis of the effects of response cards on student performance and participation in an upper division university course. Journal of Applied Behavior Analysis, 37, 405-410. http://dx.doi.org/10.1901/jaba.2004.37-405

Mayer, R. E. (2011). Applying the science of learning. Boston, MA: Pearson Education.

Mazumder, Q. H. (2012). Quality Improvement in Higher Education in Bangladesh. The Daily Sun.

Menon, G. (2008). Active Learning Pedagogy: Policy, Professional Development and classroom Performance-A case study of two post-conflict contexts: Afghanistan and Somaliland. U.S. Agency for International Development Cooperation Agreement.

Millis, B. J. (2012). Active Learning Strategies in Face-to-Face Courses. The University of Texas at San Antonio.

Millis, B., Lyman, F. T., \& Davidson, N. (1995). In H. C. Foyle (Ed.), Interactive learning in the higher education classroom (pp. 204-225). National Education Association.

Murgatroyd, S., \& Morgan, C. (1994). Total quality management in the public sector: An international perspective. Buckingham. Philadelphia: Open University Press.

Niemi, H. (2002). Active learning-A cultural change needed in teacher education in schools. Teaching and Teacher Education, 18(7), 763-780. http://dx.doi.org/10.1016/S0742-051X(02)00042-2

Niyozov, S. (2001). Understanding teaching in post-Soviet, rural, mountainous Tajikistan: Case studies of teachers' life and work. Ontario Institute for Studies in Education, University of Toronto, Toronto, CA.

Park, J. (2012). Teacher change in Bangladesh: A study of teachers adapting and implementing active learning into their practice ( $\mathrm{PhD}$ Thesis). Department of Curriculum, Teaching and Learning, Ontario Institute for Studies in Education, University of Toronto, Canada.

Policy and Operations Evaluation Department (IOB) of the Netherlands Ministry of Foreign Affairs. (2011). Education matters: Policy review of the Dutch contribution to basic education 1999-2009. No. 353. The Hague, Netherlands: Ministry of Foreign Affairs of the Netherlands.

Prince, M. (2004). Does Active Learning Work? A Review of the Research. Journal of Engineering Education, 93(3), 223-246. http://dx.doi.org/10.1002/j.2168-9830.2004.tb00809.x

Rahman, Z. (2003). Private University Education. The Daily Star. 
Reynolds, D. (1998). Schooling for literacy: A review of research on teacher effectiveness and school effectiveness and its implications for contemporary educational policies. Educational Review, 50(2), 147-162. http://dx.doi.org/10.1080/0013191980500206

Rowe, M. B. (1980). Pausing Principles and Their Effects on Reasoning in Science. In F. B. Brawer (Ed.), Teaching the Sciences: New Directions for Community Colleges (pp. 27-34). San Francisco: Jossey-Bass. http://dx.doi.org/10.1002/cc.36819803106

Serbessa, D. D. (2006). Tension between traditional and modern teaching learning approaches in Ethiopian primary schools. Journal of International Cooperation in Education, 9(1), 123-140.

Siddiqi, A. G. H. (2006). Private University in Global Perspective. Independent.

Silcock, P., \& Brundrtt, M. (2001). The Management Consequences of Different Models of Teaching and Learning. In D. Middlewood, \& N. Burton (Eds.), Managing the Curriculum. London: Paul Chapman.

Stern, D. \& Huber, G. L. (Eds.) (1997). Active Learning for Students and Teachers: Reports from Eight Countries. OECD and Peter Lang, Frankfurt am Main.

Stuart, J., \& Rutherford, R. J. (1978). Medical student concentration during lectures. The Lancet, 8088, 514-516. http://dx.doi.org/10.1016/S0140-6736 (78)92233-X

Sumon, A. G. (2004). Amendments to Streamline Private Universities. Independent.

Svinicki, M., \& Keachie, W. J. (2011). Teaching tips: Strategies, research, and theory for college and university teachers (13th ed.). Belmont, CA: Wadsworth.

The Oxford compact English dictionary. (2003). New York: Oxford University Press.

The University Grants Commission of Bangladesh. (2014). Institutional Quality Assurance Cell Operations Manual.

UNESCO. (2000). Dakar Framework for Action on Education for All. Paris: UNESCO.

UNESCO. (2004). EFA global monitoring report 2005: Education for All-the quality imperative. Paris: UNESCO.

UNICEF. (2000). Defining quality in education. Working Paper Series, Education Section Programme Division. New York, USA.

Verhoeff, T. (1997). The Role of competitions in Education. Paper presented at Future World: Educating for the 21 st Century Conference and Exhibition.

Weaver, R. A., Kowalski, T. J., \& Pfaller, J. E. (1994). Case Method Teaching in Handbook of College Teaching: Theory and Applications. Greenwood Press.

World Bank. (1995). Priorities and strategies for education. Washington, DC: The World Bank. http://dx.doi.org/10.1596/0-8213-3311-9

\section{Copyrights}

Copyright for this article is retained by the author(s), with first publication rights granted to the journal.

This is an open-access article distributed under the terms and conditions of the Creative Commons Attribution license (http://creativecommons.org/licenses/by/4.0/). 